\title{
Pengaruh Pencampuran Bahan Bakar Pertalite dengan Bio Etanol terhadap Peforma Mesin Injeksi Yamaha Vixion 150 cc Tahun 2011
}

\author{
Riva Suro Jatmiko ${ }^{1}$, Kuntang Winangun ${ }^{2}$ \\ Program Studi Teknik Mesin, Universitas Muhammadiyah Ponorogo \\ JI. Budi Utomo No. 10 Ponorogo, Jawa Timur Indonesia \\ Email: rivasurojatmiko123@yahoo.com, kuntang@umpo.ac.id
}

\begin{abstract}
This study aims to determine the effect of bio ethanol mixing with pertalite fuel on the performance of injection motorcycle engines. By presenting EO-E2O bio ethanol mixture with pertalite fuel. Performance testing parameters are torque, power, and specific fuel consumption. In this study using a test method using the dynotest tool to determine the torque and power generated from mixing the fuel. And for testing fuel consumption using the scaffolding of homemade test equipment. The result of this presentation is the right mix presentation for 150cc injection motorbikes, namely the presentation of the E15 mixture of all E15 fuel, the highest torque, power, and stable fuel consumption, not according to the power and torque produced.
\end{abstract}

Keywords: Pertalite, Bio Ethanol, Power, Torque, and Specific Fuel Consumption.

\begin{abstract}
Abstrak
Penelitian ini bertujuan untuk mengetahui pengaruh pencampuran bio etanol dengan bahan bakar pertalite terhadap peforma mesin sepeda motor injeksi. Dengan presentasi campuran bio etanol E0-E20 dengan bahan bakar pertalite. Parameter pengujian peforma yaitu torsi, daya, dan konsumsi bahan bakar spesifik. Dalam penelitian ini menggunakan metode pengujian dengan menggunakan alat dynotest untuk mengetahui torsi dan daya yang dihasilkan dari pencampuran bahan bakar tersebut. Dan untuk pengujian konsumsi bahan bakar menggunakan perancaan alat uji buatan sendiri. Hasil dari penetian ini presentasi campuran yang tepat untuk sepeda motor injeksi 150 cc yaitu pada presentasi campuran E15 dari semua bahan bakar E15paling tinggi nilai torsi, daya, dan konsumsi bahan bakarnya stabil tidak sesui dengan daya dan torsi yang dihasilkan.
\end{abstract}

Kata kunci : Pertalite, bio etanol, daya, torsi, dan konsumsi bahan bakar spesifik.

\section{Pendahuluan}

Perkembangan sepeda motor dari tahun ke tahun semakin meningkat. Hal ini mengakibatkan meningkatnya pemakaian bahan bakar minyak bumi. Dengan peningkatan pemakaian bahan bakar maka cadangan bahan bakar minyak bumi akan semakin berkurang, sedangkan kebutuhan akan bahan bakar minyak bumi akan semakin meningkat seiring perkembangan zaman.

Di Indonesia jumlah kendaraan bermotor dari tahun ke tahun mengalami kenaikan. Tahun 2014 jumlah kendaraan sepeda motor 92.976240 unit. Tahun 2015 jumlah kendaraan sepeda motor 98.881267 unit. Tahun 2016 jumlah kendaraan sepeda motor 105.150082 unit. Semua itu belum termasuk mobil penumpang, bus, dan mobil barang. Melonjaknya jumlah kendaraan dari tahun ke tahun disebabkan karena permintaan dari konsumen akan alat trasportasi semakin tinggi. Efek samping dari kenaikan jumlah kendaraan meliputi beberapa hal yaitu kemancetan, polusi, dan melonjaknya kebutuhan bahan bakar [1].

Di Indonesia Sekarang ini sepeda motor rata-rata bervolume silinder $150 \mathrm{cc}$ dan menggunakan sistem bahan bakar injeksi atau lebih dikenal dengan EFI 
(Electrical Fuel Injection) karena lebih irit bahan bakar dan proses pencampuran udara dan bahan bakar lebih sempurna dari pada menggunaakan campuran dengan karburator.

Mesin bersilinder besar kompresi diatas 10 : 1 menggunakan bahan bakar pertamax ron 92 atau pertamax plus ron 95, tetapi masyarakat cenderung menggunakan bahan bakar yang lebih murah karena harga pertamax yang lebih mahal. Masyarakat lebih memilih menggunakan bahan bakar pertalite ron 90. Pemerintah menghapus subsidi bahan bakar premium ron 88 dan menggantikannya dengan bahan bakar terbaru yaitu pertalite yang mempunyai ron 90 , lebih besar dari premium yaitu ron 88 . Akibat permintaan alat trasportasi selalu meningkat dan bahan bakar yang selalu menipis serta tidak dapat diperbarui, saat ini permerintah mengembangkan bahan bakar yang ramah lingkungan dan dapat diperbarui yaitu bahan bakar bio etanol untuk meminimalisir penggunaaan minyak bumi yang semakin meningkat.

Pada penelitian sebelumnya menguji bahan bakar pertalite dan premium untuk mengetahui pengaruh bahan bakar terhadap peforma motor. Dengan menggunaakan uji dynotest bahan bakar pertalite lebih bagus dari pada premium. Bahan bakar pertalite menghasilkan torsi 9,11 Nm, sedangkan premium menghasilkan torsi $8,59 \mathrm{Nm}$. Daya yang dihasilkan dari bahan bakar premium dan pertalite yaitu sama 8,3 dan konsumsi bahan bakar yang dihasilkan bahan bakar petalite ialah 0,0652 kg/HPjam pada putaran $4000 \mathrm{rpm}$, sedangkan bahan bakar premium menghasilkan 0,1061 $\mathrm{kg} / \mathrm{HP}$-jam pada putaran $4000 \mathrm{rpm}$ [2].

Bio etanol (etil alkohol) berasal dari tumbuh-tumbuhan seperti jagung, gandum, kentang, dan tebu. Kemudian diproses membentuk aditif yang terbaru dan menjadikan bahan bakar yang baik, dengan biaya yang efektif dan ramah lingkungan. Fungsi alkohol yaitu dapat menaikkan oktan dan mengandung oksigen sehingga menyempurnakan bahan bakar dengan efek menimalisir pencemaran udara. Bahkan alkohol juga berfungsi sebagai fuel extender, yaitu menghemat bahan bakar fosil.

Pengujian yang dilakukan peneliti sebelumnya menyebutkan bahwa menggunakan bahan pencampuran bensin dan bio etanol $(0 \%, 5 \%, 15 \%, 25 \%$ etanol). Hasil pengujian nilai kalor bahan bakar diperoleh nilai kalor premium 11.414,453 $\mathrm{kal} /$ gram; campuran etanol $5 \%=8905,921$ $\mathrm{kal} /$ gram; campuran etanol 15\% $=8717,552$ $\mathrm{kal} /$ gram; campuran etanol $25 \%=8358,941$ $\mathrm{kal} /$ gram. Hasil pengujian performansi diperoleh daya tertinggi ada pada campuran $15 \%$ yaitu $9,02 \mathrm{~kW}$ dan mampu menghabiskan $10 \mathrm{ml}$ bahan bakar dalam waktu 35,87 detik. Hasil pengujian emisi gas buang diperoleh nilai $\mathrm{CO}$ terendah ada pada campuran $25 \%$ etanol yaitu $0,85 \%$ volume udara nilai $\mathrm{CO} 2$ tertinggi ada pada campuran $25 \%$ etanol yaitu $10,6 \%$ volume udara [3].

Dengan oktan yang tinggi peforma mesin akan meningkat dan akan bekerja optimal. Mencampurkan bahan bakar pertalite dan bio etanol akan meningkatkan oktan bahan bakar setara dengan bahan bakar pertamax ron 92 bahkan bisa lebih tinggi dari pertamax, manfaat dari bio etanol yaitu mengurangi gas buang hasil pembakaran pembakaran, menghemat bahan bakar fosil dan menaikan oktan bahan bakar minyak.

\section{Tinjauan Pustaka}

\section{Sistem Electronic Fuel Injection (EFI) \\ EFI adalah suatu sistem} penyemprotan bahan bakar keruang bakar dan diatur oleh kontrol secara elektronik, Agar campuran udara dan bahan sesuai yang dibutuhkan mesin. Cara kerja EFI bahan bakar dari tangki akan ditekan ke injektor dengan fuel pump. Pada saat proses pembakaran katup in terbuka nozel injektor akan mengubah bahan bakar cair menjadi kabut dan menyemprotkanya ke intake manivold dan didorong oleh udara yang masuk keruang bakar melalui karburator. 
Komponen-komponen EFI berupa sensor dan aktuator yang di dalamnya

\section{Performa Mesin}

Menganalisis performa mesin berfungsi untuk mengetahui konsumsi bahan bakar spesifik, daya, dan torsi pada sepeda motor.

1) Daya

Daya motor adalah suatu parameter yang menentukan peforma mesin atau ujuk kerja mesin. Pengertian daya ialah kecepatan kerja motor selama selang beberapa waktu tertentu.

2) Torsi

Torsi adalah gaya tekan putar pada bagian yang berputar. Torsi ialah perkalian antara gaya pembakaran pada torak dikalikan dengan jari-jari poros engkol. Torsi dapat diperoleh dari hasil kali antara gaya dengan jarak

3) Konsumsi bahan bakar spesifik (SFC) Perhitungan konsumsi bahan bakar spesifik ini digunakan untuk mengetahui jumlah bahan bakar yang dibutuhkan pada kecepatan tertentu.

4) Perhitungan Ron (oktan) secara manual Ron merupakan sebuah angka yang menunjukkan seberapa besar tekanan yang bisa diberikan sbelum bahan bakar terbakar secara sepontan. Rumus perhitungan ron (oktan) digunakan untuk mengetahui niali ron bahan bakar.

\section{Bio Etanol}

Bio Etanol atau etil alkohol. Rumus kimia etanol adalah $\mathrm{C} 2 \mathrm{H} 5 \mathrm{OH}$ Etanol bersifat cair. Etanol dapat dibuat dari proses pemasakan, fermentasi, dan distilasi beberapa jenis tanaman seperti tebu, jagung, singkong atau tanaman lain yang kandungan karbohidatnya tinggi. Kadar bio etanol $100 \%$ tanpa campuran bernilai oktan 116.

\section{Metode Penelitian}

Untuk mencapai tujuan yang diinginkan maka dalam penelitian ini digunakan metode penelitian eksperimen. Dalam eksperimen ini pengujian dilakukan dengan memvariasikan putaran motor
(Variable Speed). Alat yang digunakan untuk pengujian menggunakan dynotest. Dalam penelitian, penggunaan bahan bakar bio etanol E0, E5, E10, E15, dan E20 dalam 1 liter. Akan dilihat hasil perubahan yang terjadi pada daya, torsi, dan konsumsi bahan bakar.

\section{Hasil dan Pembahasan}

\section{Hasil Penelitian}

Hasil penelitian ini diambil dari eksperimen yang dilakukan di Bengkel Moto Teck Indonesia, jalan Ringroad Selatan, Kemasan, Singosaren, Banguntapa, Bantul, Yogyakarta. Dengan menggunakan alat bernama dynotest untuk mengukur torsi dan daya pada mesin. Sepeda motor yang digunakan yaitu sepeda motor Yamaha Vixion 150 cc. Menggunakan bahan bakar petalite dan dicampurkan bio etanol dengan presentasi pencampuran E0, E5, E10, E15, dan E20.

Pengambilan data yang dilakukan untuk torsi dan daya menggunakan variasi kecepatan putaran yaitu 4000-10000 rpm. dan untuk pengambilan data konsumsi bahan bakar spesifik menggunakan kecepatan putaran 4000, 5000, 6000, dan $7000 \mathrm{rpm}$.

\section{Perhitungan Oktan Secara Manual}

Dari beberapa campuan bahan bakar pertalite ron 90 dan bio etanol ron 117 dapat dihitung secara manual.

a. $0 \%$ Bio etanol dan $100 \%$ pertalite

Pertalite murni tanpa campuran Ron 90

b. $5 \%$ Bio etanol dan $95 \%$ pertalite

$$
\begin{aligned}
& =\left(\frac{5}{100} \times 117\right)+\left(\frac{95}{100} \times 90\right) \\
& =\left(\frac{585}{100}\right)+\left(\frac{8550}{100}\right) \\
& =5,85+85,5 \\
& =91,35
\end{aligned}
$$

Ron pencampuran 5\% bio etanol dan 95\% pertalite adalah Ron 91,35.

c. $10 \%$ Bio etanol dan pertalite $90 \%$

$$
\begin{aligned}
& =\left(\frac{10}{100} \times 117\right)+\left(\frac{90}{100} \times 90\right) \\
& =\left(\frac{1170}{100}\right)+\left(\frac{8100}{100}\right) \\
& =11,7+81
\end{aligned}
$$


$=92,7$

Ron pencampuran $10 \%$ bio etanol dan 90\% pertalite adalah Ron 92,7.

d. $15 \%$ Bio etanol dan pertalite $85 \%$

$$
\begin{aligned}
& =\left(\frac{15}{100} \times 117\right)+\left(\frac{85}{100} \times 90\right) \\
& =\left(\frac{1755}{100}\right)+\left(\frac{7650}{100}\right) \\
& =17,55+76,5 \\
& =94,05
\end{aligned}
$$

Ron pencampuran $15 \%$ bio etanol dan $85 \%$ pertalite adalah Ron 94,05 .

e. $20 \%$ Bio etanol dan pertalite $80 \%$

$$
\begin{aligned}
& =\left(\frac{20}{100} \times 117\right)+\left(\frac{80}{100} \times 90\right) \\
& =\left(\frac{2340}{100}\right)+\left(\frac{7200}{100}\right) \\
& =23,4+72 \\
& =95,4
\end{aligned}
$$

Ron pencampuran $20 \%$ bio etanol dan $80 \%$ pertalite adalah Ron 94,05 .

\section{Torsi}

\begin{tabular}{|c|c|c|c|c|c|}
\hline \multicolumn{6}{|c|}{ Torsi (N.m) } \\
\hline $\mathrm{rpm}$ & $\begin{array}{c}\text { Pertalit } \\
\text { e EO }\end{array}$ & $\begin{array}{l}\text { Pertalit } \\
\text { e E5 }\end{array}$ & $\begin{array}{c}\text { Pertalit } \\
\text { e E10 }\end{array}$ & $\begin{array}{l}\text { Pertalit } \\
\text { e E15 }\end{array}$ & $\begin{array}{l}\text { Pertalit } \\
\text { e E20 }\end{array}$ \\
\hline 4000 & 12,076 & 12,278 & 12,24 & 11,69 & 11,438 \\
\hline 4250 & 12,06 & 12,05 & 12,402 & 12,032 & 11,802 \\
\hline 4500 & 11,99 & 11,966 & 12,202 & 12,078 & 11,924 \\
\hline 4750 & 12,02 & 11,872 & 12,146 & 12,126 & 11,936 \\
\hline 5000 & 11,916 & 11,87 & 12,112 & 12,138 & 11,946 \\
\hline 5250 & 12,212 & 12,2 & 12,414 & 12,502 & 12,27 \\
\hline 5500 & 12,558 & 12,602 & 12,848 & 12,844 & 12,682 \\
\hline 5750 & 12,864 & 12,816 & 13,09 & 13,198 & 12,952 \\
\hline 6000 & 12,928 & 12,93 & 13,162 & 13,274 & 13,11 \\
\hline 6250 & 12,982 & 13,072 & 13,282 & 13,422 & 13,122 \\
\hline 6500 & 13,148 & 13,42 & 13,618 & 13,72 & 13,614 \\
\hline 6750 & 13,64 & 13,822 & 14,044 & 14,19 & 14,12 \\
\hline 7000 & 14,12 & 14,39 & 14,588 & 14,612 & 14,542 \\
\hline 7250 & 14,448 & 14,678 & 14,874 & 14,966 & 14,908 \\
\hline 7500 & 14,644 & 14,636 & 15,028 & 15,08 & 14,996 \\
\hline 7750 & 14,544 & 14,692 & 14,954 & 15 & 14,93 \\
\hline 8000 & 14,36 & 14,45 & 14,738 & 14,81 & 14,728 \\
\hline 8250 & 14,128 & 14,21 & 14,494 & 14,54 & 14,428 \\
\hline 8500 & 13,796 & 13,946 & 14,196 & 14,308 & 14,202 \\
\hline 8750 & 13,344 & 13,47 & 13,802 & 13,874 & 13,808 \\
\hline 9000 & 12,624 & 12,82 & 13,152 & 13,284 & 13,144 \\
\hline 9250 & 11,954 & 12,144 & 12,458 & 12,588 & 12,536 \\
\hline 9500 & 11,432 & 11,628 & 11,932 & 12,1 & 12,004 \\
\hline 9750 & 10,936 & 11,15 & 11,4 & 11,608 & 11,526 \\
\hline $\begin{array}{c}1000 \\
0\end{array}$ & 10,174 & 10,432 & 10,79 & 12,782 & 10,908 \\
\hline
\end{tabular}

Dari beberapa bahan bakar tadi dengan menggunakan alat dynotest akan diketahui torsi yang paling tinggi dan campuran berapa persen yang bagus untuk kerja mesin.

Tabel 1. Torsi Semua Pengujian Pertalite E0-E20

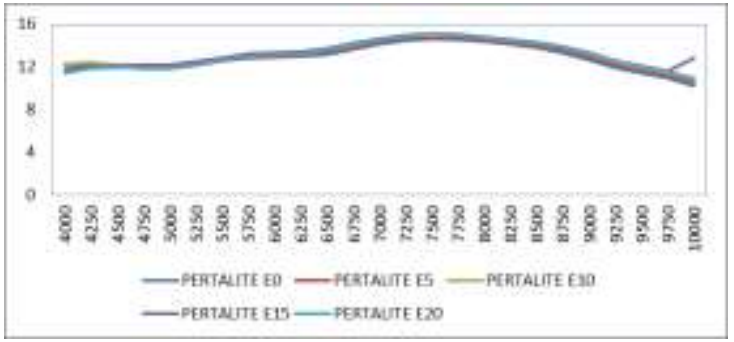

Gambar 1. Grafik Torsi Semua Pengujian Bahan Bakar Pertalite E0-E20.

Dari semua data pengujian bahan bakar yang paling bagus dan menghasilkan torsi yang paling tinggi yaitu bahan bakar pertalite E15. Bahan bakar pertalite E15 dapat dilihat dari tabel dan grafik di atas torsinya stabil dari awal putaran mesin, puncak, dan akhir putaran.

Berbeda dengan bahan bakar pertalite E20 dari perhitungan ron lebih tinggi tetapi torsinya mengalami penurunan dilihat dari grafik torsi pertalite E20 bio etanol torsinya stabil tetapi torsinya lebih rendah.

Pada bahan bakar campuran E10 dapat dilihat dari tabel dan grafik pada rpm bawah menengah puncak dan akhir seperti bergelombang bahan bakar seperti tidak stabil dan pada bahan bakar campuran E5 bio etanol pada rpm putaran bawah naik habis itu turun pada rpm menengah naik sampai titik pucak sama seperti campuran bio etanol E10 torsi yang dihasilkan bergelombang pada putaran bawah bahan bakar yang kurang stabil.

Dari beberapa bahan bakar tadi dengan menggunakan alat dynotest akan diketahui daya yang paling tinggi dan campuran berapa persen yang bagus untuk kerja mesin. 
Tabel 2. Daya Setiap Hasil Pengujian Pertalite E0-E20

\begin{tabular}{cccccc}
\hline \multicolumn{5}{c}{ DAYA } \\
\hline RPM & EO & E5 & E10 & E15 & E20 \\
\hline 4000 & 6,8 & 6,9 & 6,88 & 6,56 & 6,4 \\
\hline 4250 & 7,18 & 7,22 & 7,4 & 7,18 & 7,04 \\
\hline 4500 & 7,6 & 7,56 & 7,72 & 7,64 & 7,52 \\
\hline 4750 & 8,02 & 7,92 & 8,14 & 8,12 & 7,98 \\
\hline 5000 & 8,38 & 8,36 & 8,54 & 8,54 & 8,38 \\
\hline 5250 & 9,02 & 9,02 & 9,18 & 9,26 & 9,04 \\
\hline 5500 & 9,72 & 9,78 & 9,96 & 9,92 & 9,8 \\
\hline 5750 & 10,44 & 10,38 & 10,58 & 10,64 & 10,46 \\
\hline 6000 & 10,92 & 10,94 & 11,12 & 11,24 & 11,08 \\
\hline 6250 & 11,42 & 11,5 & 11,675 & 11,8 & 11,72 \\
\hline 6500 & 12,02 & 12,3 & 12,5 & 12,56 & 12,5 \\
\hline 6750 & 12,98 & 13,16 & 13,36 & 13,5 & 13,44 \\
\hline 7000 & 13,9 & 14,24 & 14,42 & 14,42 & 14,34 \\
\hline 7250 & 14,8 & 15,02 & 15,2 & 15,3 & 15,2 \\
\hline 7500 & 15,46 & 15,6 & 15,88 & 15,92 & 15,84 \\
\hline 7750 & 15,88 & 16,04 & 16,34 & 16,42 & 16,32 \\
\hline 8000 & 16,24 & 16,34 & 16,62 & 16,7 & 16,62 \\
\hline $\mathbf{8 2 5 0}$ & $\mathbf{1 6 , 4 4}$ & 16,52 & 16,9 & 16,92 & 16,82 \\
\hline 8500 & 16,6 & $\mathbf{1 6 , 7 8}$ & $\mathbf{1 7 , 0 6}$ & $\mathbf{1 7 , 1 4}$ & $\mathbf{1 7 , 0 8}$ \\
\hline 8750 & 16,5 & 16,62 & $\mathbf{1 7 , 0 6}$ & $\mathbf{1 7 , 1 4}$ & 17,06 \\
\hline 9000 & 16,04 & 16,3 & 16,72 & 16,86 & 16,72 \\
\hline 9250 & 15,62 & 15,86 & 16,28 & 16,46 & 16,36 \\
\hline 9500 & 15,34 & 15,62 & 16 & 16,22 & 16,12 \\
\hline 9750 & 15,08 & 15,38 & 15,74 & 16,02 & 15,9 \\
\hline 10000 & 14,38 & 14,74 & 15,26 & 15,54 & 15 \\
\hline & & & & &
\end{tabular}

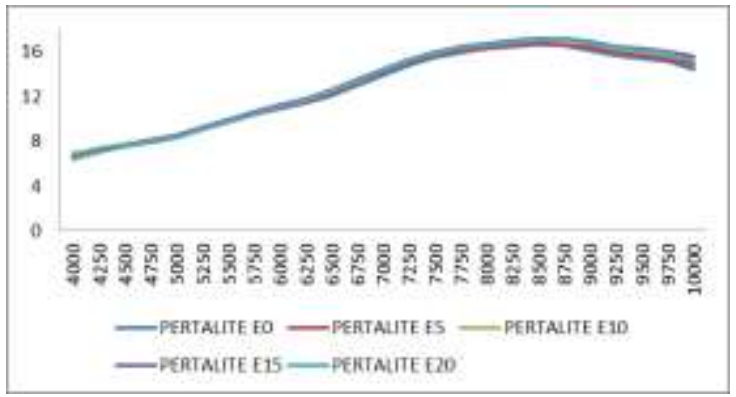

Gambar 2. Grafik Daya Semua Pengujan Pertalite E0-20

Dari hasil semua pengujian campuran bahan bakar pertalite E15 yang paling tinggi dari semua campuran. Bahan bakar dengan campuran E15 menghasilkan daya $17,14 \mathrm{~kW}$ pada rpm 8500 dan 8750 sedanglan campuran E20 hanya menghasilkan daya $17,08 \mathrm{~kW}$ pada rpm 8500 dari segi ron campuran E20 bio etanol lebih tinggi dibandingkan dengan campuran E15 bio etanol tetapi saat di uji malah sebaliknya yang paling tinggi campuran E15 dibandingkan E20.

\section{Konsumsi Bahan Bakar Spesifik}

Berdasarkan hasil pengujian konsumsi bahan bakar dalam 1 strip bahan bakar setara dengan $6,25 \mathrm{ml}$ atau $6,25 \mathrm{cc}$ dan diperoleh data sebagai berikut.
Pada hasil pengujian konsumsi bahan bakar spesifik dari tabel dan grafik di atas, dapat dijelaskan konsumsi bahan bakar menggunakan bahan bakar pertalite E0 atau bisa disebut pertalite murni. Pada putaran rpm 4000 untuk menghabiskan satu strip yang senilai $6,25 \mathrm{cc}$ membutuhkan waktu sekitar 45,2 detik dan konsumsi bahan bakar spesifiknya $0,053 \mathrm{~kg} / \mathrm{jam}$.HP menghasilkan daya $6,8 \mathrm{~kW}$ Pada putaran 5000 membutuhkan waktu 34,74 detik untuk satu stripnya, menghasilkan daya 8,3 $\mathrm{kW}$ dan konsumsi bahan bakar spesifiknya $0,055 \mathrm{~kg} / \mathrm{jam} . \mathrm{HP}$ meningkat konsumsi bahan bakarnya dari putaran 4000-5000 rpm meningkat $0,002 \mathrm{~kg} / \mathrm{jam} . \mathrm{HP}$, konsumsi bahan bakar spesifik E0-E20.

Tabel 3. Konsumsi Bahan Bakar Spesifik Pertalite E0-20

\begin{tabular}{cccccc}
\hline & \multicolumn{5}{c}{ Konsumsi bahan bakar spesifik Kg/Jam.HP } \\
\cline { 2 - 6 } rpm & $\begin{array}{c}\text { Pertalit } \\
\text { e E0 }\end{array}$ & $\begin{array}{c}\text { Pertalit } \\
\text { e E5 }\end{array}$ & $\begin{array}{c}\text { Pertalite } \\
\text { E10 }\end{array}$ & $\begin{array}{c}\text { Pertalite } \\
\text { E15 }\end{array}$ & $\begin{array}{c}\text { Pertalite } \\
\text { E20 }\end{array}$ \\
\hline $\begin{array}{c}4 \mathrm{r} \\
\mathrm{b}\end{array}$ & 0,053 & 0,045 & 0,049 & 0,051 & 0,048 \\
\hline $\begin{array}{c}5 \mathrm{r} \\
\mathrm{b}\end{array}$ & 0,055 & 0,046 & 0,045 & 0,045 & 0,045 \\
\hline $\begin{array}{c}6 \mathrm{r} \\
\mathrm{b}\end{array}$ & 0,045 & 0,049 & 0,046 & 0,041 & 0,046 \\
\hline $\begin{array}{c}\mathrm{7r} \\
\mathrm{b}\end{array}$ & 0,056 & 0,045 & 0,054 & 0,054 & 0,054 \\
\hline
\end{tabular}

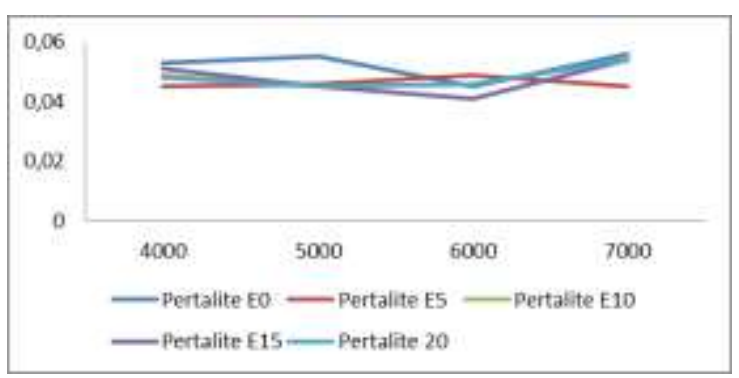

Gambar 3. Grafik Konsumsi Bahan Bakar Spesifik Pertalite E0-E20

Dapat dilihat dari tabel 3 dan grafik 3 dijadikan satu akan kelihatan dari pengujian bahan bakar E0-E20. Pada campuran E15 atau pertalite $85 \%$ dan bio etanol $15 \%$ yang paling stabil bahan bakarnya karena pada putaran 4000-6000 rpm mengalami penurunan daya dan torsi yang dihasilkan dari bahan bakar tersebut lebih tinggi. Dan pada putaran $7000 \mathrm{rpm}$ bahan bakar mengalami peningkatan karena untuk memperoleh daya dan torsi yang lebih besar. 
Berbeda dengan bahan bakar E5 atau pertalite $95 \%$ bio etanol $5 \%$, pada putaran atas atau puncak bahan bakar malah mengalami penurunan maka hasilnya torsi dan daya yang dihasilkan lebih rendah.

Pada bahan bakar E10 atau pertalite $90 \%$ bio etanol 10\% pada putaran rpm 6000 sudah mengalami peningkatan bahan bakar. Hal ini menyebabkan borosnya konsumsi bahan bakar dan menghasilkan torsi dan daya yang kurang stabil. Ini juga terjadi pada bahan bakar E20 sama pada putaran 6000 sudah mengalami peningkatan bahan bakar.

\section{Kesimpulan}

Dari data hasil penelitian pengaruh pencampuran bahan bakar pertalite dengan bio etanol terhadap performa mesin injeksi Yamaha Vixion $150 \mathrm{cc}$ tahun 2011 dapat diambil kesimpulan bahwa sangat berpengaruh bahan bakar pertalite dicampur dengan bio etanol terhadap performa mesin daya, torsi, dan konsumsi bahan bakar. Bahkan ron bahan bakar meningkat. Torsi yang paling tingggi dan stabil yaitu pada bahan bakar dengan campuran E15 atau pertalite $85 \%$ bio etanol $15 \%$ pada bahan bakar ini torsi yang dihasilkan paling tinggi dari semua campuran yaitu 15,08 Nm pada putaran $7500 \mathrm{rpm}$. Daya yang dihasilkan dari semua pengujian yang paling tinggi yaitu pada campuran E15 daya yang dihasilkan ialah $17,14 \mathrm{~kW}$ pada putaran 8500 dan $8750 \mathrm{rpm}$. Presentasi yang tepat untuk mesin injeksi bersilinder $150 \mathrm{cc}$ yaitu pada presentasi campuran bahan bakar pertalite E15. Di bawah E15 torsi dan daya yang dihasilkan meningkat tetapi di pengujian konsumsi bahan bakar itu tidak stabil dalam peningkatan performa mesin dan di atas E15 daya dan torsi yang dihasilkan lemah dan konsumsi bahan bakar tidak stabil.

\section{Saran}

Untuk penelitian selanjutnya diharapkan bisa menerapkan bio etanol dengan presentasi E50-E100 dan menggunakan media yang berbeda. Untuk mengurangi ketergantungan terhadap bahan bakar minyak bumi dan menciptakan bahan bakar terbaru yang ramah lingkungan.

\section{Referensi}

[1]. https://databoks.katadata.co.id/datapu blish/2017/12/20/2016-

jumlah-sepeda-motor-

indonesia-tembus-100-juta,

10 juli 2018

[2]. Muamar Ilham, (2016). Pengaruh

Bahan Bakar Pertalite Dan

Premium Terhadap Peforma

Mesin Motor Yamaha Jupiter-

Z Cw Tahun 2010. Uiversitas

Muhammadiyah Pontianak.

[3]. Fintas Afan Agrariksa, Bambang

Susilo, dan Wahyunanto

Agung Nugroho (2013) judul

penelitian adalah Uji

Performansi Motor bakar

Bensin (On Chassis)

Menggunakan Campuran

Premium dan Etano.

[4]. Philip Kristanto. Dkk. (2015). Motor

Bakar Torak Dan Aplikasinya. Yogyakarta : Cv Andi. 